\title{
Kesehatan telinga siswa Sekolah Dasar Inpres 1073 Pandu
}

\author{
${ }^{1}$ Sylvester B. Demmassabu \\ ${ }^{2}$ Ora I. Palandeng \\ ${ }^{2}$ Olivia C Pelealu
}

\author{
${ }^{1}$ Kandidat Skripsi Fakultas Kedokteran Universitas Sam Ratulangi Manado \\ ${ }^{2}$ Bagian/SMF Telinga Hidung Tenggorok-Bedah Kepala Leher Universitas Sam Ratulangi \\ Email: Demmassabu@gmail.com
}

\begin{abstract}
Ear is very important in hearing and balancing. This study aimed to obtain the ear health status of students of Inpres 10/73 Elementary School at Pandu. This was a descriptive observational study with a cross sectional design. Subjects were students of 10/73 Pandu Elementary School. The results showed that from the 18 respondents of this study there were 8 male and 10 female students. The examination of earlobe resulted in all (100\%) students had normal ear lobes. The ear canal examination showed that $88.89 \%$ of students had normal ear canals, and $11.11 \%$ of students had cerumen. The examination of tympanic membranes showed that $61.11 \%$ of students had normal tympanic membrane, meanwhile $38.89 \%$ of students had perforated or retracted tympanic membrane. Conclusion: Most of the students had normal ear health status,
\end{abstract}

Keywords: ear health, ear examination

\begin{abstract}
Abstrak: Telinga adalah organ tubuh yang berperan penting pada proses pendengaran dan keseimbangan. Penelitian ini bertujuan untuk mengetahui gambaran kesehatan telinga pada siswa-siswi SD Inpres 10/73 Pandu. Jenis penelitian ini deskriptif observasional dengan pendekatan potong lintang. Sampel penelitian ialah siswa-siswi kelas V SD Inpres 10/73 Pandu. Jumlah responden 18 siswa/i terdiri dari 8 anak laki-laki dan 10 anak perempuan. Pada pemeriksaaan daun telinga didapatkan $100 \%$ normal. Pada pemeriksaan liang telinga didapatkan $88,89 \%$ normal dan $11,11 \%$ terdapat serumen. Pada pemeriksaan membran timpani persentase normal $61,11 \%$ dan persentase anak yang terdapat perforasi dan retraksi 38,89\%. Simpulan: Sebagian besar siswa/i mempunyai kesehatan telinga normal.
\end{abstract}

Kata kunci: kesehatan telinga, pemeriksaan telinga

Telinga adalah organ tubuh yang berperan penting pada proses pendengaran dan keseimbangan, karena alat pendengaran dan alat keseimbangan ada di dalam telinga. Telinga terbagi atas telinga luar, telinga tengah dan telinga dalam. Gangguan pada telinga luar dan telinga tengah dapat menyebabkan tuli konduktif, sedangkan gangguan telinga dalam menyebabkan tuli sensorineural. ${ }^{1,2}$

Perkiraan World Health Organization (WHO) pada tahun 2005 terdapat 278 juta orang di dunia menderita gangguan pendengaran, 75-140 juta diantaranya terdapat di Asia Tenggara. ${ }^{3}$ Saat ini WHO memperkirakan ada 360 juta (5,3\%) orang di dunia mengalami gangguan pendengaran, 328 juta (91\%) diantaranya orang dewasa (183 juta laki-laki dan 145 juta perempuan) dan 32 juta (9\%) ialah anakanak. Prevalensi gangguan meningkat seiring dengan pertambahan usia. Prevalensi gangguan pendengaran pada orang di atas usia 65 tahun bervariasi dari 18 sampai hampir 50\% di seluruh dunia. Di Indonesia gangguan pendengaran dan 
ketulian saat ini masih merupakan satu masalah yang dihadapi masyarakat. Berdasarkan hasil Survei Nasional Kesehatan Indera Penglihatan dan Pendengaran di 7 provinsi tahun 19921995, prevalensi ketulian $0,4 \%$ dan gangguan pendengaran 16,9\%. Penyebabnya ialah infeksi telinga tengah $(3,1 \%)$, presbikusis (2,5\%), tuli akibat obat ototoksik (0,2\%), tuli sejak lahir /kongenital $(0,1 \%)$ dan tuli akibat pemaparan bising. ${ }^{3}$

Gangguan pendengaran mengakibatkan anak sulit menerima pelajaran, produktivitas menurun, dan biaya hidup tinggi. Informasi dapat diserap 20\% melalui proses mendengar. Hal ini lebih besar dibanding membaca yang hanya menyerap $10 \%$ informasi. ${ }^{3}$ Menurut Information Center for Children and Youth with Disabilities, anak dengan gangguan pendengaran mengalami kesulitan untuk mempelajari kosakata, tatabahasa, kata perintah, ungkapan, dan aspek lainnya dari komunikasi verbal dibandingkan dengan anak normal. ${ }^{3}$

Pada tahun 1970-an, sebagian besar penduduk Indonesia tidak menyelesaikan pendidikan dasar. Pada saat itu jumlah SD masih sangat terbatas sedangkan jumlah anak-anak usia SD diperkirakan akan meningkat mengingat sebelumnya belum ada program KB. Oleh karena itu kemudian pemerintah meluncurkan program pembangunan sekolah dasar secara besar-besaran. Karena merupakan program khusus maka diluncurkan melalui Instruksi Presiden sehingga terjadi peningkatan jumlah penduduk yang menyelesaikan pendidikan dasar dikarenakan adanya tekanan maka sekolah dijadikan crash program. ${ }^{4}$

\section{METODE PENELITIAN}

Penelitian ini bersifat deskriptif observasional dengan pendekatan potong lintang. Penelitian ini dilaksanakan di SD Inpres 10/73 Pandu Kecamatan Bunaken pada tanggal 16 Oktober 2015. Populasi penelitian ialah siswa/siswi SD 10/73 Pandu. Sampel penelitian ialah siswa/siswi SD 10/73 Pandu Kelas V Pemeriksaan telinga luar dan dalam meliputi inspeksi, palpasi, dan otoskopi. Pemeriksaan inspeksi telinga luar melihat bentuk daun telinga, besar, dan serta melihat adanya sekret atau serumen. Pemeriksaan palpasi untuk mengetahui apakah ada benjolan atau pembengkakan terjadi pada telinga luar. Pemeriksaan menggunakan otoskop untuk melihat bagian liang telinga serta membran timpani apakah ada perforasi, retraksi serta hiperemis.

Data hasil pemeriksaan diisi pada tabel pemeriksaan THT yang telah disusun menggunakan Microsoft Word 2013 kemudian data diolah menggunakan Microsoft Excel 2013

\section{HASIL PENELITIAN}

Responden penelitian ini berasal dari SD Inpres 10/73 Pandu. Jenis kelamin terbanyak ialah perempuan berjumlah 10 anak (55,56\%) dan sisanya laki-laki berjumlah 8 anak $(44,44 \%)$.

Tabel 1.Tabel berdasarkan jenis kelamin siswa siswi SD Inpres 10/73 Pandu.

\begin{tabular}{ccc}
\hline Kelamin & $\mathrm{N}$ & $(\%)$ \\
\hline Laki-laki & 8 & 44,44 \\
Perempuan & 10 & 55,56 \\
Total & 18 & 100,00 \\
\hline
\end{tabular}

Tabel 2. Tabel persentase berdasarkan usia siswa-siswi SD Inpres 10/73 Pandu

\begin{tabular}{ccc}
\hline Umur & $\mathrm{N}$ & $(\%)$ \\
\hline 9 tahun & 8 & 44,44 \\
10 tahun & 9 & 50,00 \\
12 tahun & 1 & 5,56 \\
Total & 18 & 100 \\
\hline
\end{tabular}

Tabel 3. Tabel persentase hasil pemeriksaan bagian daun telinga siswa-siswi SD Inpres 10/73 Pandu

\begin{tabular}{lllll}
\hline \multirow{2}{*}{$\begin{array}{l}\text { Daun } \\
\text { Telinga }\end{array}$} & $\mathrm{N}$ & \multicolumn{2}{c}{$(\%)$} \\
\cline { 2 - 5 } Kanan & Kiri & Kanan & Kiri \\
\hline Normal & 18 & 18 & 100 & 100 \\
\hline Abnormal & 0 & 0 & - & - \\
\hline Total & 18 & 18 & 100 & 100 \\
\hline
\end{tabular}


Tabel 4. Tabel persentase hasil pemeriksaan bagian liang telinga siswa-siswi SD Inpres 10/73 Pandu.

\begin{tabular}{lcccc}
\hline \multirow{2}{*}{ Liang } & \multicolumn{3}{c}{$\mathrm{N}$} & \multicolumn{2}{c}{ Persentase (\%) } \\
\cline { 2 - 5 } Telinga & Kanan & Kiri & Kanan & Kiri \\
\hline Normal & 16 & 15 & 88,89 & 83,33 \\
Normal + & & & & \\
Cerumen & 2 & 3 & 11,11 & 16,67 \\
Hiperemis & 0 & 0 & 0,00 & 0,00 \\
Serumen & 0 & 0 & 0,00 & 0,00 \\
Sekret & 0 & 0 & 0,00 & 0,00 \\
Debris & 0 & 0 & 0,00 & 0,00 \\
Furunkel & 0 & 0 & 0,00 & 0,00 \\
Udim & 0 & 0 & 0,00 & 0,00 \\
Total & 18 & 18 & 100,00 & 100,00 \\
\hline
\end{tabular}

Tabel 5. Tabel persentase hasil pemeriksaan membran timpani siswa-siswi SD Inpres 10/73 Pandu

\begin{tabular}{ccccc}
\hline Membran & \multicolumn{2}{c}{$\mathrm{N}$} & \multicolumn{2}{c}{ Persentase (\%) } \\
\cline { 2 - 5 } Timpani & Kanan & Kiri & Kanan & Kiri \\
\hline Normal & 13 & 13 & 72,22 & 72,22 \\
\hline Perforasi & 3 & 3 & 16,67 & 16,67 \\
\hline Retraksi & 2 & 2 & 11,11 & 11,11 \\
\hline Bombans & 0 & 0 & 0,00 & 0,00 \\
\hline Suram & 0 & 0 & 0,00 & 0,00 \\
\hline Hiperemis & 0 & 0 & 0,00 & 0,00 \\
\hline Total & 18 & 18 & 100,00 & 100,00 \\
\hline
\end{tabular}

\section{BAHASAN}

Pada pemeriksaan kesehatan telinga pada siswa-siswi kelas V SD Inpres 10/73 Pandu terdapat 18 responden dengan persentase terbanyak pada perempuan (55,56\%) dan sisanya laki-laki (44,44\%) dengan kisaran umur 9-12 tahun.

Dari hasil pemeriksaan didapatkan sebagian besar anak memperlihatkan hasil normal, namun terdapat beberapa anak yang mengalami perforasi pada telinga kanan (16,67\%) dan telinga kiri (16,67\%).

Hasil pemeriksaan daun telinga kanan maupun kiri pada responden semuanya memperlihatkan hasil normal yang sejalan dengan penelitian Gosal et al. yang mendapatkan pada pemeriksaan masyarakat pesisir pantai Bahu 31 orang (100\%) dengan keadaan daun telinga normal. ${ }^{5}$

Pada pemeriksaan liang telinga siswasiswi SD Inpres 10/73 Pandu, didapatkan hasil normal telinga kanan maupun kiri dengan jumlah persentase $(88,89 \%)$ pada telinga kanan dan (83,33\%) pada telinga kiri. Terdapat beberapa hasil yang didapatkan normal disertai adanya serumen persentasenya sebanyak (11,11\%) pada telinga kanan dan (16,67\%) pada telinga kiri. Hiperemis, furunkel, hingga udim tidak ditemukan pada siswa-siswi di sekolah ini. Penelitian sebelumnya oleh Gosal et al. ${ }^{5}$ pada masyarakat pesisir pantai Bahu didapatkan keadaan liang telinga normal kiri dan kanan sebanyak 24 orang (77,4\%), ditemukan juga serumen telinga kiri dan kanan sebanyak 7 orang (22,6\%).

Serumen memiliki fungsi proteksi, tetapi dapat mengumpul dan membentuk masa serumen obsturan yang menyumbat liang telinga. Berbagai faktor berkaitan dalam pembentukan serumen yaitu faktor internal seperti kelainan bentuk anatomis liang telinga, sekret serumen berlebihan, kelainan sistemik, aktifitas bakteri dan jamur dalam liang telinga berperan dalam pembentukan serumen obsturan. Faktor eksternal seperti cara membersihkan liang telinga, kelembaban udara yang tinggi, serta lingkungan yang berdebu juga berperan dalam pembentukan serumen obsturan. ${ }^{6,7}$

Pada pemeriksaan membran timpani di SD Inpres 10/73 Pandu didapatkan hasil normal antara telinga kanan dan kiri sama banyak pada siswa-siswi kelas $\mathrm{V}$ dengan persentase $(61,11 \%)$, sedangkan pada hasil pemeriksaan membran timpani perforasi pada telinga kanan dan kiri dengan persentase (16,67\%) dan (16,67,\%). Hasil pemeriksaan pada telinga kanan dan kiri yang ada retraksi sama persentasenya (11,11\%). Hasil pemeriksaan lain seperti ada bombans dan hiperemis tidak ditemukan pada siswa-siswi di SD ini. ${ }^{23}$ Pada hasil survey sebelumnya di daerah pesisir pantai Bahu ditemukan membran timpani normal kiri dan kanan sebanyak 24 orang $(77,4 \%)$, perforasi telinga kiri dan kanan sebanyak 2 orang (6,5\%). Perforasi dapat disebabkan oleh karena infeksi seperti otitis media supuratif baik akut maupun kronik, kolesteatoma, barotrauma. 
Usia sekolah dasar juga cenderung masih harus diperhatikan kebersihan telinganya agar tidak mengganggu dalam proses belajar mengajar maupun keseharian sang anak di sekolah. ${ }^{7,8}$

Dari hasil penelitian ini dapat kita perhatikan bahwa status kesehatan telinga siswa siswi SD Inpres 10/73 Pandu sebagian besar sudah sangat baik. Dalam hal ini mungkin dipengaruhi oleh begitu banyaknya artikel artikel maupun berita tentang kesehatan telinga yang berada di dunia internet dan mudah untuk diakses serta dibaca secara langsung. Lain daripada itu juga letak geografis dari masyarakat di daerah Pandu wilayahnya sudah lebih berkembang kearah kelurahan yang berada di kota Manado dibanding desa beberapa yang ada di sekitar. Faktor intelektual dan pekerjaan juga salah satu yang berperan penting dalam kesehatan telinga masyarakat disini, dikarenakan kebiasaankebiasaan membersihkan serta menjaga kebersihan telinga sudah menjadi hal yang penting dalam kehidupan mereka seharihari. Penemuan lain seperti ditemukannya serumen pada liang telinga diperlukan edukasi untuk pentingnya pemeriksaan serta penanganan yang lebih baik di klinik mapun rumah sakit yang memiliki fasilitas yang lebih lengkap.

Peneliti juga menyadari bahwa hasil penelitian ini masih mempunyai banyak kekurangan dan keterbatasan sehingga belum bisa dijadikan tolok ukur untuk status kesehatan telinga secara umum dan luas dikarenakan masih kurangnya jumlah populasi sampel yang berada di sekolah ini untuk diteliti. Selain itu, terdapat beberapa siswa yang belum hadir atau tidak datang saat akan dilakukan pemeriksaan. Hal ini disebabkan karena mereka masih khawatir dan takut pada dokter yang akan melakukan pemeriksaan di sekolah ini.

\section{SIMPULAN}

Berdasarkan hasil penelitian kesehatan telinga pada siswa SD Inpres 10/73 Pandu tanggal 16 Oktober 2015 terdiri dari 18 anak-anak, dengan jumlah terbanyak adalah perempuan yaitu 10 anak dan laki-laki 8 anak. Rata-rata pada pemeriksaan dalam menggunakan otoskop didapatkan hasil normal, namun ada beberapa siswa yang hasil pemeriksaannya ditemukan perforasi pada membran timpani. Hal ini disebabkan oleh kebiasaan anak tersebut membersihkan telinga bagian dalam dengan benda asing.

\section{SARAN}

Perlu dilakukan penyuluhan kesehatan telinga, hidung dan tenggorok yang diolah oleh pemerintah dapat dilakukan kepada masyarakat untuk lebih peduli terhadap kesehatan telinga, hidung, dan tenggorok lebih khusus pada siswa-siswi SD di Kelurahan Pandu. Survei kesehatan telinga sebaiknya lebih ditekankan khusus pada orang tua dan anak-anak yang masih kurang peduli terhadap kesehatan telinga.

Bagi para penderita gangguan telinga yang ringan ataupun berat, sebaiknya perlu dilakukan konsultasi ke Rumah Sakit pada bagian THT-KL, agar dapat dikonsultasi pada dokter spesialis THT-KL, supaya dapat diberikan pemeriksaan serta pengobatan yang memadai.

\section{DAFTAR PUSTAKA}

1. Soepandi EA, Iskandar N, Basshirudin J, Restuti RD. Buku Ajar Ilmu Kesehatan Telinga Hidung Tenggorok Kepala \& Leher (6th ed). Jakarta: Badan penerbit FKUI, 2007.

2. Dhingra PL. Diseases of the nose, throat, ear, head and neck (4th ed). India: Elsevier, 2007.

3. Depkes RI. Pendengaran Sehat untuk Hidup Bahagia [homepage on the internet]. Nodate [cited 2015 Sep23]. Available from:

http://www.depkes.go.id/index.php?v $\mathrm{w}=2 \& \mathrm{id}=2245$

4. De Kromo Isroi. "Sekolah di SD Inpres”.[Cited : 24 September 2015]. Available from: http://www.isroi.com/2008/03/08/sek olah-di-sd-inpres/

5. Gosal R, Palandeng OI, Pelealu O. Survei kesehatan telinga masyarakat pesisir pantai Bahu. eCliniC. 2015;3(2).

6. Nagel P, Gurkov R. Dasar-dasar ilmu THT (2nd ed). Jakarta: EGC, 2012. 
Jurnal e-Clinic (eCl), Volume 4, Nomor 1, Januari-Juni 2016

7. Soetjipto D, Mangunkusumo E, Wardani RS. Buku Ajar Ilmu Kesehatan Telinga Hidung Tenggorok Kepala \& Leher (7th ed). Jakarta: Balai penerbit FKUI, 2012.
8. Hilger PA. Hidung: Anatomi dan fisiologi terapan. In: Adams GL, Boeis LR, Higler PA, editors. Boeis Buku Ajar Penyakit THT (6th ed). Jakarta: EGC, 1997; p. 170-90. 